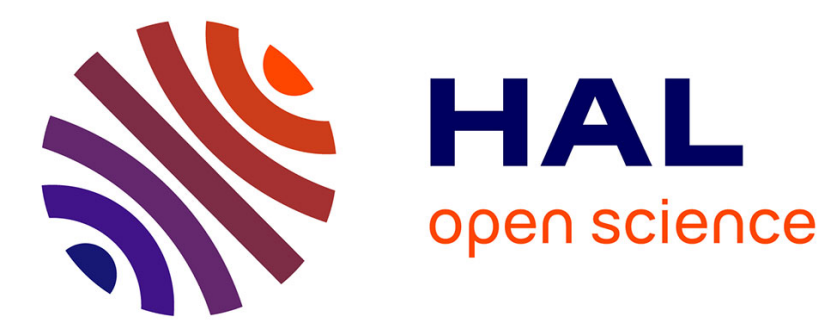

\title{
High temperature sulfidation of pack-tantalized iron
}

\author{
A. Galerie, F. Passier, X. Nguyen Khac, M. Caillet
}

\section{To cite this version:}

A. Galerie, F. Passier, X. Nguyen Khac, M. Caillet. High temperature sulfidation of pack-tantalized iron. Journal de Physique IV Proceedings, 1993, 03 (C9), pp.C9-331-C9-337. 10.1051/jp4:1993933 . jpa-00252371

\section{HAL Id: jpa-00252371 https://hal.science/jpa-00252371}

Submitted on 1 Jan 1993

HAL is a multi-disciplinary open access archive for the deposit and dissemination of scientific research documents, whether they are published or not. The documents may come from teaching and research institutions in France or abroad, or from public or private research centers.
L'archive ouverte pluridisciplinaire HAL, est destinée au dépôt et à la diffusion de documents scientifiques de niveau recherche, publiés ou non, émanant des établissements d'enseignement et de recherche français ou étrangers, des laboratoires publics ou privés. 


\title{
High temperature sulfidation of pack-tantalized iron
}

\author{
A. Galerie, F. Passier, X. Nguyen Khac and M. Caillet
}

Laboratoire Science des Surfaces et Matériaux Carbonés, URA CNRS $n^{\circ}$ 413, E.N.S. d'Electrochimie et d'Electrométallurgie de Grenoble, Institut National Polytechnique de Grenoble, BP 75, Domaine Universitaire, F-38402 Saint-Martin d'Hères, France

\begin{abstract}
The tantalization of iron in a pack containing $\mathrm{Ta}, \mathrm{CrF}_{2}$ and alumina leads to a duplex coating containing $\mathrm{TaFe}+\mathrm{TaFe}_{2}$ in the internal part and nearly pure $\mathrm{Ta}$ containing iron in the external part. The kinetics of tantalization are parabolic due to the limitation by a gas phase diffusional mechanism. Tantalized iron samples were submitted to flowing $\mathrm{Ar}-\mathrm{H}_{2} \mathrm{~S}$ mixtures at temperatures between 500 and $700^{\circ} \mathrm{C}$ and the kinetics followed continuously with a magnetic suspension balance. Due to the very low sulfidation rates, great care was taken to the amount of residual $\mathrm{H}_{2} \mathrm{O}$ in the sulfidizing gas. The formed product was always $\mathrm{FeS}$, with no evidence of Ta sulfide(s). This compound was shown to grow by outward transport of Fe from the bulk through the Ta-rich external layer of the coating. The kinetics exhibit a first decreasing rate period followed by a constant rate regime. A model of diffusion-reaction explains correctly the experimental results. The decreasing rate period corresponds to transitory effects leading to steady state boundary condition where the rate law becomes linear. Calculated curves fit correctly the experimental results and reaction and diffusion data are derived.
\end{abstract}

\section{Introduction.}

Degradation of metals and alloys by high temperature oxidation is easily reduced by application of appropriate coatings containing either chromium, aluminium or silicon. In the case of purely sulfidizing atmospheres, the problem is more severe and no satisfactory solution has emerged. Systematic experiments by Mrowec showed that refractory metals exhibit very low sulfidation rates and can become good candidates for coating application [1, 2]. The present work describes the use of tantalum in a diffusion coating deposited on iron substrate by pack cementation and subsequently submitted to $\mathrm{H}_{2} \mathrm{~S}$ corrosion. Contrary to other refractory metals, tantalum sulfidation was seldom studied and very few references are available [3]. The present work is therefore also a contribution to tantalum reactivity knowledge.

\section{Elaboration of the coatings.}

Iron samples $(15 \times 15 \times 1.5 \mathrm{~mm})$ were tantalized during $50 \mathrm{~h}$ at $1050^{\circ} \mathrm{C}$ in a pack containing $40 \mathrm{wt} \% \mathrm{Ta}, 50 \mathrm{wt} \% \mathrm{Al}_{2} \mathrm{O}_{3}$ and $10 \mathrm{wt} \% \mathrm{CrF}_{2}$ as an activator. In such conditions, tantalization takes place parabolically with a rate constant $K_{\mathrm{p}}=2.5 \times 10^{-7} \mathrm{~kg}^{2} \mathrm{~m}^{-4} \mathrm{~s}^{-1}$.

The tantalized samples exhibited a two layers structure (Fig. 1):

- an external layer ( $10 \mu \mathrm{m}$ thick) consisting of nearly pure tantalum (with little Fe and $\mathrm{Cr}$ in solid solution);

- an internal layer ( $40 \mu \mathrm{m}$ thick) exhibiting a biphased morphology ( $\mathrm{TaFe}+\mathrm{TaFe} 2)$. 


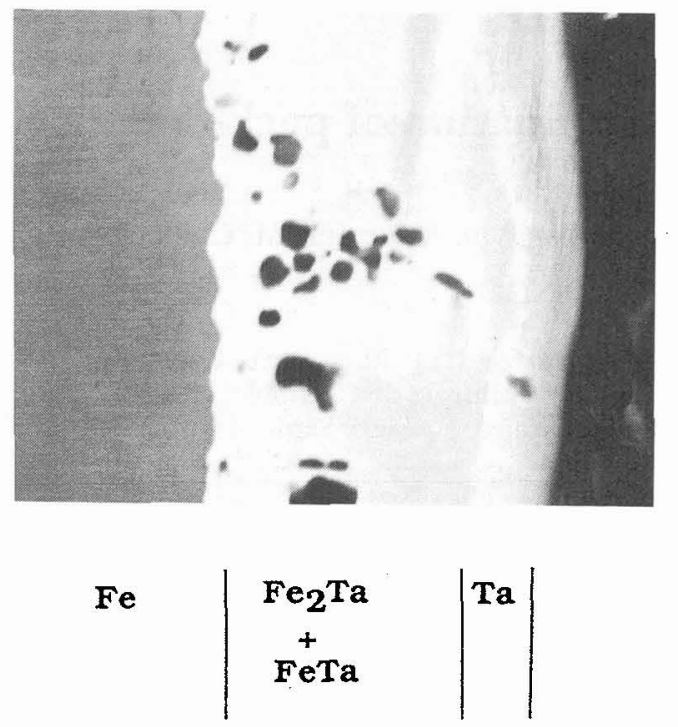

Fig. 1. - Cross section of an iron sample tantalized at $1050{ }^{\circ} \mathrm{C}$ during 50 hours.

The overall growing rate was shown to be controlled by a mixed regime involving slow gas phase diffusion and interface reaction [4].

\section{Sulfidation of tantalized specimens.}

3.1 EXPERIMENTAL. - Isothermal sulfidation kinetics were followed during $50 \mathrm{~h}$ in a dynamic $\left(0.5 \mathrm{~cm} \mathrm{~s}^{-1}\right) \mathrm{Ar}-5 \% \mathrm{H}_{2} \mathrm{~S}$ mixture at atmospheric pressure $\left(50 \mathrm{hPa} \mathrm{H}_{2} \mathrm{~S}\right)$ in order to evacuate hydrogen produced by the reaction. A magnetic suspension balance (Sartorius) was used. The temperature was varied between 500 and $700^{\circ} \mathrm{C}$. Under $500{ }^{\circ} \mathrm{C}$, weight gains were very low; above $700^{\circ} \mathrm{C}$ massive sulfur deposits on the magnet and suspension hook led to non valid measurements.

Great care was taken to the residual water vapor in the gas. With no precautions, corrosion of pure tantalum and tantalized iron by $\mathrm{Ar}_{-} \mathrm{H}_{2} \mathrm{~S}$ led to the rapid formation of $\mathrm{Ta}_{2} \mathrm{O}_{5}$. A $50 \mathrm{~cm}$ long fresh $\mathrm{P}_{2} \mathrm{O}_{5}$ trap was therefore used for all experiments and allowed to suppress any oxide formation.

3.2 KINETICS. - Kinetic curves obtained for sulfidation of superficially tantalized iron are reported in figure 2 and compared with sulfidation of pure iron and pure tantalum. It may be observed that tantalization inhibits markedly (about ten times) the sulfidation of iron, but cannot reduce it to that of pure tantalum. The rate law exhibits a first decreasing period (5 to 6 hours long) before remaining linear. Careful examinations of the first period showed that the initial rate has a finite value. The activation energy derived for the linear part of the kinetic curves was found to be $44 \mathrm{~kJ} \mathrm{~mol}^{-1}$. 


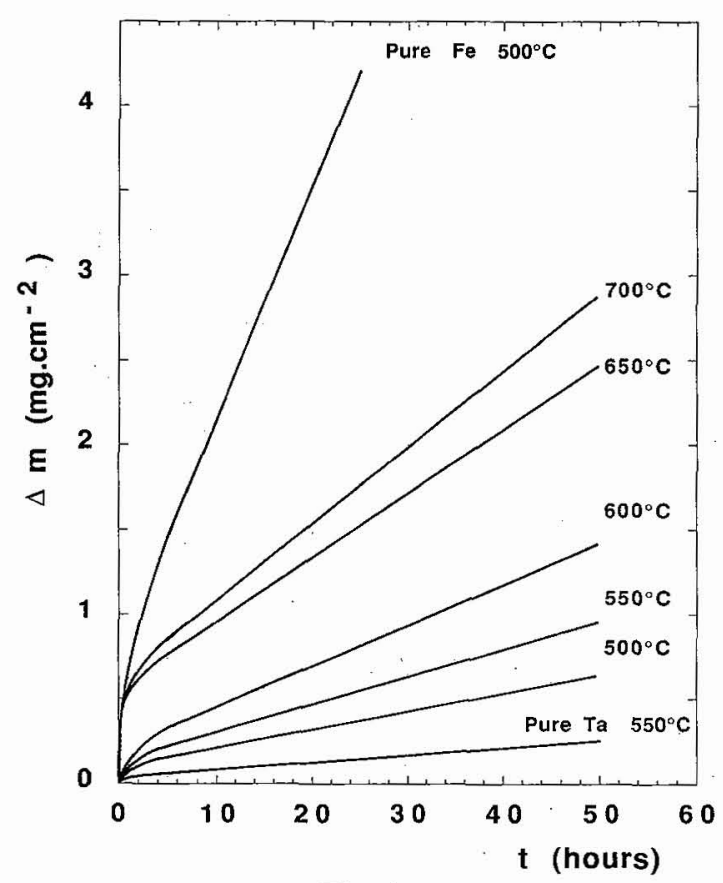

Fig. 2.

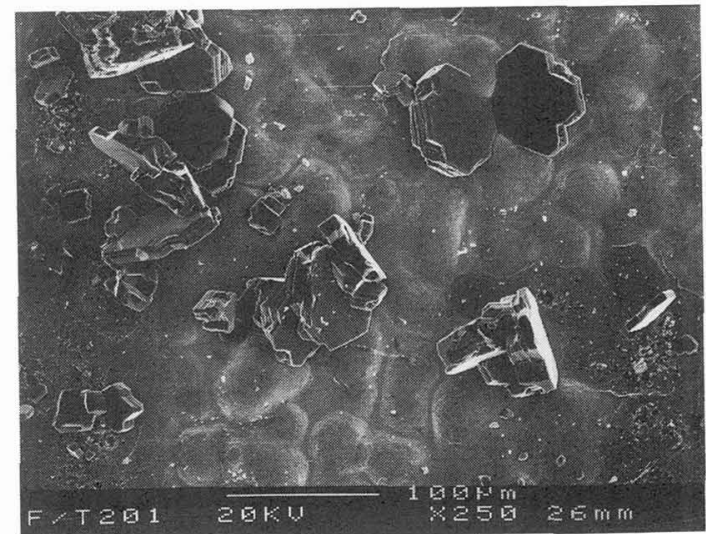

Fig. 3.

Fig. 2. - Kinetic curves of sulfidation at different temperatures by $\mathrm{H}_{2} \mathrm{~S}$ of tantalized iron. Comparison with iron and tantalum sulfidation.

Fig. 3. - Surface view of a tantalized specimen sulfidized at $500{ }^{\circ} \mathrm{C}$ during 55 hours.

3.3 FORMED PRODUCTS AND MORPHOLOGY OF THE SCALES. - For all the duration and temperature ranges explored, only FeS was observed without any trace of tantalum sulfide(s). Iron sulfide appeared as large crystals, scattered on the surface for the lowest temperatures, closely joined for the highest (Figs. 3, 4).

Cross-section examinations showed that the coating was not modified during sulfidation. In particular, the thickness of the external Ta-rich layer remained constant (Fig. 5).

3.4 Discussion. - Experimental observations that tantalum sulfide(s) did not form during sulfidation are not in agreement with thermodynamics. Indeed the sulfur $\left(\mathrm{S}_{2}\right)$ pressures in equilibrium with $\mathrm{TaS}_{2}$ and $\mathrm{FeS}$ at $500^{\circ} \mathrm{C}$ are in the order $10^{-20}$ and $10^{-10}$ bar respectively. $\mathrm{TaS}_{2}$ is therefore the most thermodynamically stable sulfide, but its rate of formation is infinitely low. FeS forms at a rate depending on iron concentration at the Ta/FeS interface. This concentration decreases continuously due to the slow diffusion rate of $\mathrm{Fe}$ in the $\mathrm{Ta}$ layer and tends to a lower limit when stationnary conditions are achieved. Such a mixed kinetic regime can be described as presented in figure 6, using the expressions of the iron diffusion flux:

$$
J_{\mathrm{Fe}}=D \frac{\left(C_{\mathrm{i}}^{\circ}-C_{\mathrm{e}}\right)}{y}
$$




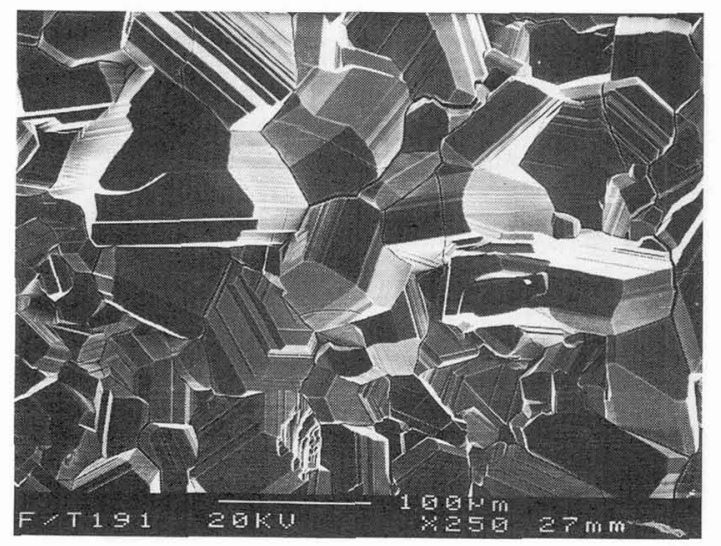

Fig. 4.

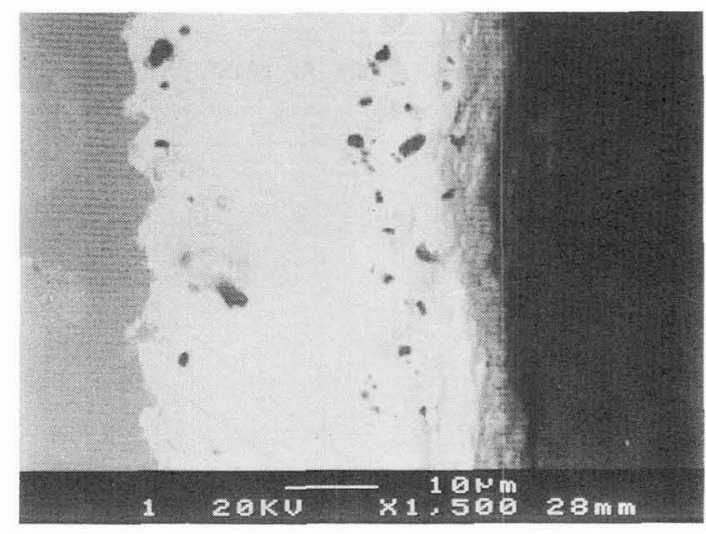

$\mathrm{Fe}\left|\begin{array}{c}\mathrm{Fe}_{2} \mathrm{Ta} \\ +\mathrm{FeTa}\end{array}\right| \quad \mathrm{Ta} \mid\{\mathrm{FeS}$

Fig. 5 .

Fig. 4. - Surface view of a tantalized specimen sulfidized at $650^{\circ} \mathrm{C}$ during 45 hours.

Fig. 5. - Cross section of a tantalized specimen sulfidized at $650^{\circ} \mathrm{C}$ during 50 hours.

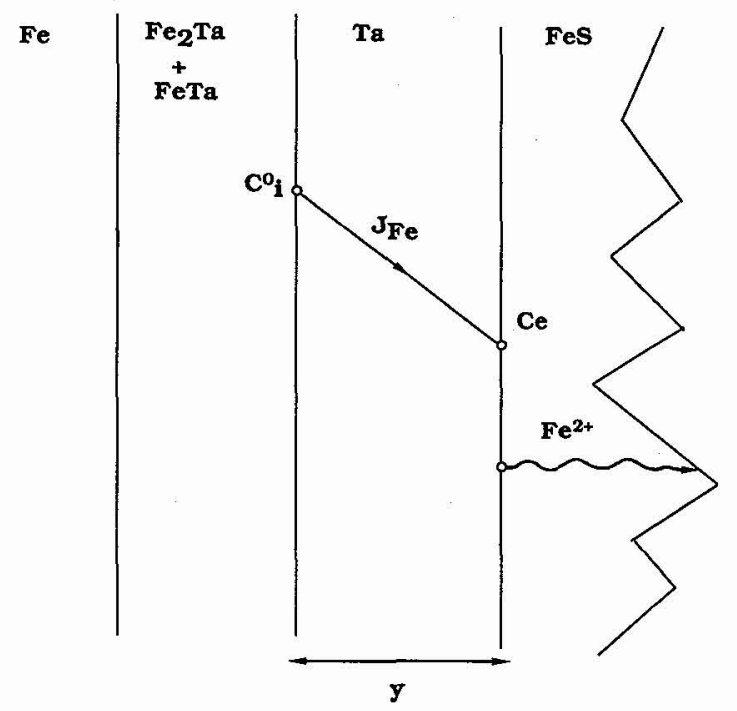

Fig. 6. - Schematic representation of the tantalized specimen during sulfidation (actual scale not respected). 
and of the interface reaction rate:

$$
V=k C_{\mathrm{e}}
$$

(with $J_{\mathrm{Fe}}$ : iron flux in the external tantalum layer of the coating, $y$ : thickness of this layer, $C_{\mathrm{i}}^{\circ}$ : equilibrium Fe concentration at the interface between the two layers of the coating, $C_{\mathrm{e}}$ : Fe concentration at the $\mathrm{Ta} / \mathrm{FeS}$ interface, $D:$ Fe diffusion coefficient in the Ta layer, $V:$ rate of sulfidation of iron, $k$ : interfacial rate constant).

At the $\mathrm{Ta} / \mathrm{FeS}$ interface, the mass balance imposes:

$$
\frac{\mathrm{d} C_{\mathrm{e}}}{\mathrm{d} t}=\left(\frac{\mathrm{d} C_{\mathrm{e}}}{\mathrm{d} t}\right)_{\text {diffusion }}-\left(\frac{\mathrm{d} C_{\mathrm{e}}}{\mathrm{d} t}\right)_{\text {reaction }}
$$

It is therefore easily understood why the rate law is firstly decreasing due to an initial reaction rate higher than the diffusion flux. During this transitory period, $C_{\mathrm{e}}$ decreases continuously. When $C_{\mathrm{e}}$ achieves a stationary value where reaction rate and diffusion flux are equal, the rate law becomes linear.

Introducing the thickness " $a$ " of the reactive interface [5], $C_{\mathrm{e}}$ can be calculated from:

$$
\frac{\mathrm{d} C_{\mathrm{e}}}{\mathrm{d} t}=\frac{D}{a} \frac{C_{\mathrm{e}}-C_{\mathrm{i}}}{y}-\frac{k}{a} C_{\mathrm{e}}
$$

leading to:

$$
C_{\mathrm{e}}=\frac{k y C_{\mathrm{i}}^{\circ}}{D+k y} \exp \left(-\frac{D+k y}{a y}\right) t+\frac{D C_{\mathrm{i}}^{\circ}}{D+k y}
$$

It can be verified that $C_{\mathrm{e}}=C_{\mathrm{i}}^{\circ}$ for $t=\mathrm{o}$ and that $C_{\mathrm{e}}$ decreases continuously with time, tending to:

$$
C_{e_{\text {limit }}}=\frac{D C_{\mathrm{i}}^{\circ}}{D+k y}
$$

The reaction rate is:

$$
\frac{1}{\mathrm{~d} t} \mathrm{~d}\left(\frac{\Delta m}{A}\right)=k M_{\mathrm{S}} C_{\mathrm{e}}
$$

(with $\frac{\Delta m}{A}$ : weight gain per unit area, $M_{\mathrm{S}}$ : atomic mass of sulfur), leading, by integration, to:

$$
\frac{\Delta m}{A}=a M_{\mathrm{S}}\left(\frac{k y}{D+k y}\right)^{2} C_{\mathrm{i}}^{\circ}\left[1-\exp \left(-\frac{D+k y}{a y}\right) t\right]+\frac{k M_{\mathrm{S}} D C_{\mathrm{i}}^{\circ}}{D+k y} t
$$




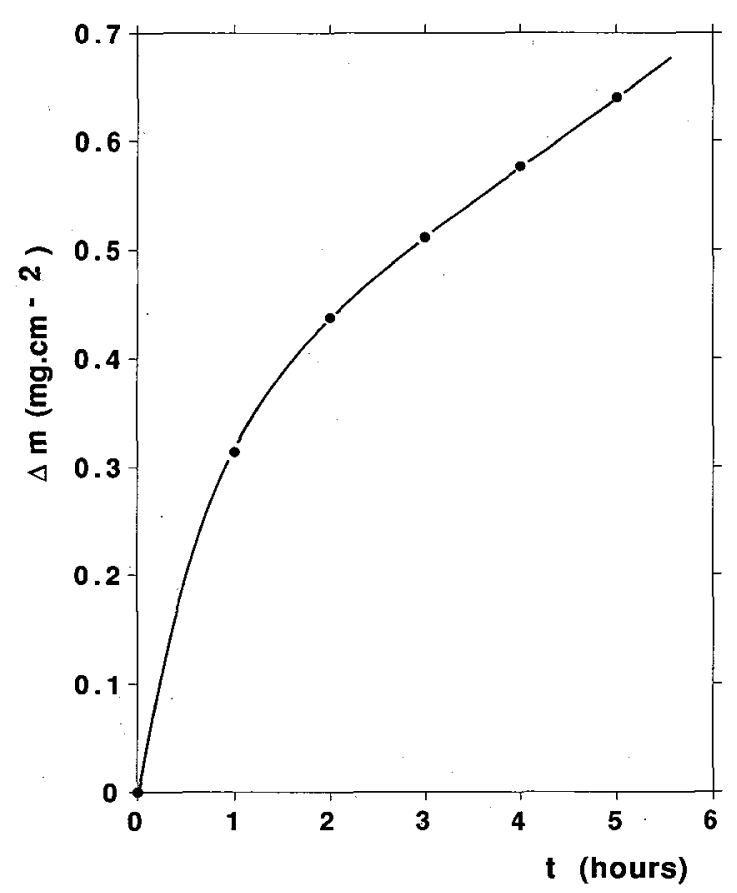

Fig. 7. - Comparison between the calculated curve and the experimental points for the sulfidation at $650^{\circ} \mathrm{C}$ of tantalized iron.

Figure 7 shows that this theoretical equation fits well the experimental results. From the measured values of:

- the initial rate: $\frac{1}{\mathrm{~d} t} \mathrm{~d}\left(\frac{\Delta m}{A}\right)_{\mathrm{o}}=M_{\mathrm{S}} k C_{\mathrm{i}}^{\circ}$

- the rate in stationnary conditions: $\frac{1}{\mathrm{~d} t} \mathrm{~d}\left(\frac{\Delta m}{A}\right)_{\text {stat. }}=\frac{M_{\mathrm{S}} k C_{\mathrm{i}}^{\circ}}{D+k y}$

- the ordinate at the origin: $\left(\frac{\Delta m}{A}\right)_{\mathrm{o}}=M_{\mathrm{S}} a C_{\mathrm{i}}^{\circ}\left(\frac{k y}{D+k y}\right)$, average values of $a, D$ and $k$ can be derived in the $500-700^{\circ} \mathrm{C}$ temperature range. These values lie in the following intervals:

$a: 7 \times 10^{-12}$ to $3.5 \times 10^{-11} \mathrm{~m} ; D: 2 \times 10^{-15}$ to $9 \times 10^{-15} \mathrm{~m}^{2} \mathrm{~s}^{-1} ; k: 1 \times 10^{-10}$ to $7 \times 10^{-9} \mathrm{~m} \cdot \mathrm{s}^{-1}$.

Calculated values of $k$ cannot be discussed, but the realistic values obtained for $a$ and $D$ may be a positive argument for the validity of the model.

\section{Conclusions.}

Superficial tantalization affords an important inhibition of iron sulfidation in $\mathrm{H}_{2} \mathrm{~S}$ at 500$700^{\circ} \mathrm{C}$. The tantalum-rich solid solution containing a little iron and chromium acts as a diffusion barrier for iron atoms which are therefore slowly converted into FeS. The sulfidation rate is initially decreasing during the establishment of an iron gradient within the diffusion 
layer (transitory period). When steady-state boundary conditions are achieved, the rate becomes constant. A mixed regime, involving two limiting steps leads to calculated curves fitting well the experimental results. The physical parameters derived from this model were shown to be realistic.

\section{References}

[1] Mrowec S., PrZybylski K., High. Temp. Mater. Processes 6 (1984) 1.

[2] Mrowec S., PrZYBYlski K., Oxid. Met. 23 (1985) 107.

[3] DutrizaC J., J. Less Common. Met. 85 (1982) 55.

[4] Passier F., Nguyen khac X., Schouler M.C., Galerie A., Caillet M., Mem. Et. Sci. Rev. Metall. (Feb. 1993) p. 273.

[5] Azzopardi M., Caillet M., Sarrazin P., Besson J., J. Chim. Phys. 6 (1974) 858. 